\title{
Medical Supplies Shortages and Burnout among Greek Health Care Workers during Economic Crisis: a Pilot Study
}

George Rachiotis ${ }^{1 凶}$, Christos Kourousis² ${ }^{2}$ Maria Kamilarakiㄹ, Emmanouil K. Symvoulakis³, George Dounias $^{2}$, and Christos Hadjichristodoulou ${ }^{1}$

1. Department of Hygiene and Epidemiology, Medical Faculty, School of Science University of Thessaly, Larisa, Greece;

2. Department of Occupational and Industrial Hygiene. National School of Public Health. Athens. Greece;

3. Private Family Practice Unit in Heraklion, Crete, Greece.

$\triangle$ Corresponding author: E-Mail: grach@med.uth.gr.

(c) Ivyspring International Publisher. This is an open-access article distributed under the terms of the Creative Commons License (http://creativecommons.org/ licenses/by-nc-nd/3.0/). Reproduction is permitted for personal, noncommercial use, provided that the article is in whole, unmodified, and properly cited.

Received: 2013.10.10; Accepted: 2014.02.12; Published: 2014.03.II

\begin{abstract}
Greece has been seriously affected by the economic crisis. In 201 I there were reports of $40 \%$ reduction to public hospital budgets. Occasional shortages of medical supplies have been reported in mass media. We attempted to pivotally investigate the frequency of medical supplies shortages in two Greek hospital units of the National Health System and to also assess their possible impact on burnout risk of health care workers. We conducted a cross-sectional study $(n=303)$ of health care workers in two Greek hospitals who were present at the workplace during a casually selected working day (morning shift work). The Maslach Burnout Inventory (MBI) was used as the measure of burnout. An additional questionnaire was used about demographics, and working conditions (duration of employment, cumulative night shifts, type of hospital including medical supplies shortages and their impact on quality of healthcare. The prevalence of emotional exhaustion, depersonalization and low personal accomplishment was $44.5 \%, 43.2 \%$ and $51.5 \%$, respectively. Medical supply shortages were significantly associated with emotional exhaustion and depersonalization. This finding provides preliminary evidence that austerity has affected health care in Greece. Moreover, the medical supply shortages in Greek hospitals may reflect the unfolding humanitarian crisis of the country.
\end{abstract}

Key words: medical supplies shortages, burnout, Maslach Burnout Inventory

\section{Introduction}

Burnout syndrome is a multidimensional psychological response to chronic interpersonal job stressors. It is characterized by emotional exhaustion, feelings of cynicism and detachment from the job. Burnout consist of three dimensions: emotional exhaustion (EA) which refers to the depletion of worker's emotional resources and is considered the main stress dimension of burnout; depersonalization (DP) seen as the effect of emotional exhaustion and refers to detachment and, eventually, dehumanization; and reduced personal accomplishment (PA), a dimension that reflects reduced feelings of competence and productivity at work $[1,2]$.

Greece has been seriously affected by the economic crisis beginning in 2007. The rescue package adopted in 2010 came with conditions of stringent austerity [3]. In 2011 there were reports of $40 \%$ reduction to public hospital budgets. In addition, occasional shortages of medical supplies have been reported in mass media $[4,5]$. Recently, a shipping container filled with more than $650,000 \$$ worth of medical supplies and equipment was bound for the AHEPA (American 
Hellenic Educational Progressive Association) Hospital in Northern Greece due to the efforts of various charity organizations [6]. There is limited qualitative information that health care workers are worried about the scarcity of resources and in particular, about lack of medical supplies [7]. To the best of our knowledge there is no published data on the association between medical supplies shortages and burnout among health care workers. Consequently, the aim of this study was to pivotally investigate the frequency of medical supplies shortages in two Greek hospitals of the National Health System (N.H.S.) and to also assess their possible impact on burnout risk of health care workers.

\section{Material and methods}

\section{Study design}

We conducted a cross-sectional study among a convenient sample of health care workers in two Greek hospitals who were present at the workplace during one casually selected working day (morning shift work). We aimed to create a pool of respondents from distant and different level of urbanization regions. One of the most and one of the less population dense regions of Greece were selected, Attica and Thessaly respectively. Two hospitals of the Greek N.H.S (one tertiary and one secondary level of care) were included in order to averagely balance microenvironment differences within our sample. For this reason it is planned to treat data as totals and to not compare different source responses. In particular, one tertiary hospital unit has been selected randomly among all the third level of care units of Athens, Attica. Region of Attica sprawls over $3,800 \mathrm{~km}^{2}$ and reaches 3,827,624 inhabitants (Census 2011). Population density in Attica is estimated at 1000 per $\mathrm{km}^{2}$. The other hospital included is located in Thessaly area. Region of Thessaly, mainly agricultural and reaching 732,762 inhabitants (Census 2011) covers over $14,000 \mathrm{~km}^{2}$ with a population density of 52 per $\mathrm{km}^{2}$. A questionnaire was used collecting information on demographics (sex, age, education, marital status, occupation) and working conditions (duration of employment, cumulative night shifts, type of hospital including medical supplies shortages. In addition, participants were asked about the security of their working position. In particular, respondents were asked to rate the presence of medical supplies shortages during the last 12 months on a five point Likert scale ranging from 0 (never) to 5 (always). Additionally, they were asked to rate if medical material shortages had a negative impact on the quality of health care provided to the patients on a five point Likert scale ranging from fully disagree to fully agree.
Further, participants were asked if they feel that their working position is insecure during the last 12 months (options ranged from never to always). Additionally, respondents asked to state if their rest after a night work shift is sufficient (options ranged from fully disagree to fully agree). The Maslach Burnout Inventory (MBI) was used as the measure of burnout [8].The MBI consist of 22 questions that evaluated the three components of burnout in particular: emotional exhaustion (9 items), depersonalization (5 items) and lack of personal accomplishment (8 items). Participants were asked to rate the presence of burnout symptoms on a 7-point Likert-scale ranging from 0 (never) to 6 (daily). Independent scores were calculated for each of the three components of burnout. These scores have been classified to low, moderate and high. In particular, scores on emotional exhaustion scale $\geq 27$, on depersonalization scale $\geq 10$, and on lack of personal accomplishment $\leq 33$ have been considered high [9]. The high burnout outcomes for all dimensions were compared to average and low ones for statistical analyses. Regarding validation of the MBI, a Cronbach's has been calculated for the three dimensions of burnout. The values of Cronbach's were $0.92,0.76$ and 0.86 for emotional exhaustion, depersonalization, and lack of personal accomplishment, respectively.

\section{Statistical analysis}

All data collected were entered a database created within Epi Info 2000 software. Absolute (n) and relative frequencies (\%) were presented for qualitative variables while mean (standard deviation) or median was used for the presentation of continuous variables. Chi-square test was used for the Univariate analysis of qualitative variables and student's $t$-test or Mann Whitney for the univariate analysis of continuous data. Continuous data were assessed for normality using Kolmogorov -Smirnoff test. Logistic regression analysis was used in order to identify factors independently associated with the high scores in the dimensions of emotional exhaustion, depersonalization and low personal accomplishment, respectively. Three models of logistic regression analyses were employed. In each model the dependent variable was the high score in the dimensions of emotional exhaustion, depersonalization and personal accomplishment, respectively. Adjusted odds ratios (OR) with 95\% Confidence Intervals (95\% C.I.) were calculated. The level of statistical significance was set at 0.05 .

All participants gave their informed consent and the protocol of the study was approved by the Hospitals' Ethics Committees. The questionnaires were completed through face to face interview. The study 
was completed in April 2013.

\section{Results}

The number of workers in the two hospitals was approximately 1400. In particular, 303 out of 450 health care workers who were approached accepted to participate in the study. The response rate was $74 \%$. Table 1 shows the basic socio-demographic information of the participants. The participants were predominantly female $(71 \%)$ and the mean age was 39 years (SD: 9). Regarding occupation $49.5 \%$ of the participants belonged to nursing staff, $26.1 \%$ were physicians, $15.6 \%$ were paramedics and $8.9 \%$ were clerical workers. An interesting finding is that $88 \%(267 / 303)$ of the participants reported significant medical supply shortages during the last 12 months. Moreover, $84 \%$ of the participants that experienced medical supply shortages reported that these shortages had a negative impact on the quality of healthcare provided to the patients. The prevalence of emotional exhaustion, depersonalization and low personal accomplishment was $44.5 \%, 43.2 \%$ and $51.5 \%$, respectively.

Table I. Basic characteristics of the participants.

\begin{tabular}{ll}
\hline Characteristic & N/Total (\%) or Mean (SD) \\
\hline Sex & $88 / 303(29 \%)$ \\
Male & $215 / 203(71 \%)$ \\
Female & $39(9)$ \\
Age (mean, SD) & $12(8)$ \\
Duration of employment (mean, SD) & 552 \\
Cumulative night shifts (median) & \\
Education & $14(9.5 \%)$ \\
High School & $20(13.5 \%)$ \\
Lyceum & $15(10.1 \%)$ \\
Vocational Training & $41(27.7 \%)$ \\
Technological & $55(37.2 \%)$ \\
University & $3(2 \%)$ \\
Msc, PhD & \\
Family status & $191(63 \%)$ \\
Married & $74(24.5 \%)$ \\
Single & $17(5.5 \%)$ \\
Divorced & $8(2.6 \%)$ \\
Windowed & $13(4.4 \%)$ \\
Cohabitation & \\
Occupation & $79(26.1 \%)$ \\
Physician & $150(49.5 \%)$ \\
Nursing & $74(24.4 \%)$ \\
Paramedical &
\end{tabular}

\section{Univariate and multivariate analysis of emotional exhaustion}

Table 2 lists the univariate analysis of emotional exhaustion. Workers with high emotional exhaustion were compared to their colleagues with medium and low exhaustion (control group). Cumulative amount of night shifts, absence of satisfactory rest after a night shift, occupation (being a nurse or physician), medical supplies shortages, and type of hospital (tertiary university vs. secondary) were variables significantly associated with the prevalence of emotional exhaustion. Multivariate logistic regression analysis (Table 3) showed that age (continuous variable), occupation, medical supplies shortages, type of hospitals and unsatisfactory rest after night shift were independently associated with the presence of emotional exhaustion among health care workers.

Table 2. Univariate analysis of emotional exhaustion.

\begin{tabular}{|c|c|c|c|}
\hline Variable & $\begin{array}{l}\text { Emotional ex- } \\
\text { haustion }(+)^{*}\end{array}$ & $\begin{array}{l}\text { Emotional ex- } \\
\text { haustion (-) }\end{array}$ & $\begin{array}{l}P \\
\text { value }\end{array}$ \\
\hline $\operatorname{Sex}^{b}$ & n (\%) & n (\%) & \\
\hline Male & $47 / 88(53.4 \%)$ & $41 / 88(46.6 \%)$ & $0.056^{\mathrm{b}}$ \\
\hline Female & $88 / 215(40.9 \%)$ & $127 / 215(59.1 \%)$ & \\
\hline Age (years) a & $40.04(8.58)$ & $38.7(9.4)$ & $0.21^{\mathrm{c}}$ \\
\hline $\begin{array}{l}\text { Cumulative night } \\
\text { shifts }^{\text {a }}\end{array}$ & $640(623)$ & $491(569)$ & $0.023^{b}$ \\
\hline \multicolumn{4}{|l|}{$\begin{array}{l}\text { Satisfactory rest after } \\
\text { nightshift }{ }^{b}\end{array}$} \\
\hline No & $71 / 126(56.3) \%$ & $55 / 126(43.7 \%)$ & \\
\hline Yes & $64 / 176(36.4 \%)$ & $112 / 176(63.6 \%)$ & 0.001 \\
\hline \multicolumn{4}{|l|}{$\begin{array}{l}\text { Medical supplies } \\
\text { shortages }^{\mathrm{b}}\end{array}$} \\
\hline Yes & $126 / 135(93.3 \%)$ & $129 / 168(76.8 \%)$ & $<0.001$ \\
\hline No & $9 / 135(6.7 \%)$ & $39 / 168(23.2 \%)$ & \\
\hline \multicolumn{4}{|l|}{ Occupation $^{\mathrm{b}}$} \\
\hline Nurses/physicians & $110 / 228(48.2 \%)$ & $118 / 228(51.8 \%)$ & 0.024 \\
\hline Paramedical & $25 / 75(33 \%)$ & $50 / 75(67 \%)$ & \\
\hline \multicolumn{4}{|l|}{ Family status ${ }^{b}$} \\
\hline Married/cohabited & $87 / 204(42.6 \%)$ & $117 / 204(57.4 \%)$ & 0.3 \\
\hline $\begin{array}{l}\text { Single/divorced/ } \\
\text { windowed }\end{array}$ & $37 / 99(37.4 \%)$ & $62 / 99(62.6 \%)$ & \\
\hline \multicolumn{4}{|l|}{ Type of hospital ${ }^{b}$} \\
\hline Tertiary/University & $94 / 148(63.5 \%)$ & $54 / 148(36.5 \%)$ & $<0.001$ \\
\hline Secondary & $41 / 155(26.5 \%)$ & $114 / 155(73.5 \%)$ & \\
\hline
\end{tabular}

Table 3. Multivariate analysis of emotional exhaustion.

\begin{tabular}{lll}
\hline Independent variables & \multicolumn{2}{c}{ Emotional exhaustion $(+)$} \\
\cline { 2 - 3 } & OR $(95 \% \mathrm{CI})$ & P value \\
\hline $\begin{array}{l}\text { Age } \\
\text { Occupation }\end{array}$ & $1.07(1.03-1.17)$ & 0.001 \\
$\begin{array}{l}\text { Nurses/physicians } \\
\text { Others }\end{array}$ & $3.53(1.79-6.95)$ & \\
Medical supplies shortages & $1.00(\mathrm{ref})$ & $<0.001$ \\
Yes & $2.92(1.21-7.02)$ & 0.016 \\
No & $1.00($ ref $)$ & \\
Type of hospital & & \\
$\begin{array}{l}\text { Tertiary/University } \\
\text { Secondary }\end{array}$ & $3.88(2.13-7.06)$ & $<0.001$ \\
$\begin{array}{l}\text { Satisfactory rest after night } \\
\text { shift }\end{array}$ & $1.00($ ref $)$ & \\
Yes & & \\
No & $1.00($ ref $)$ & 0.029 \\
\hline
\end{tabular}


In particular, nursing personnel and physicians recorded a 3.5 fold increased risk (OR=3.53; 95\% C.I.=1.79-6.95) of reporting emotional exhaustion in comparison to other health care workers. Additionally, medical supply shortages was an independent risk factor for emotional exhaustion (Odds Ratio= 2.92, 95\% C.I $=1 \cdot 21-7.02)$. In particular, health care workers who reported medical supplies shortages recorded an almost three fold increased risk of suffering emotional exhaustion in comparison with their colleagues who did not report shortages.

Absence of satisfactory rest after night shift was found to be an independent risk factor for emotional exhaustion. Health care workers with unsatisfactory rest after night shift had an almost two fold risk of emotional exhaustion in comparison to employees who reported satisfactory rest $(\mathrm{OR}=1.82$; $95 \%$ C.I. $=1.06-3.13)$. Type of hospital was the stronger determinant of emotional exhaustion. Health care workers at a tertiary/university hospital recorded a 3.88 fold risk of emotional exhaustion in comparison to their colleagues working at a secondary hospital $(\mathrm{OR}=3.88$; 95\% C.I. $=2.13-7.06)$.

Table 4. Univariate analysis of depersonalization (DP).

\begin{tabular}{|c|c|c|c|}
\hline Variable & $\mathrm{DP}(+)^{*}$ & DP (-) & $\begin{array}{l}P \\
\text { value }\end{array}$ \\
\hline Sex $^{b}$ & n (\%) & n (\%) & \\
\hline Male & $47 / 88(53.4 \%)$ & $41 / 88(46.6 \%)$ & $0.022^{b}$ \\
\hline Female & $84 / 215(39.1 \%)$ & $131 / 215(60.9 \%)$ & \\
\hline Age (years) a & $39.18(8.34)$ & $39.3(9.62)$ & $0.9^{c}$ \\
\hline $\begin{array}{l}\text { Cumulative night } \\
\text { shifts }\end{array}$ & $575(534)$ & $572(597)$ & $0.537 \mathrm{~d}$ \\
\hline \multicolumn{4}{|l|}{$\begin{array}{l}\text { Satisfactory rest } \\
\text { after nightshift }{ }^{b}\end{array}$} \\
\hline No & $71 / 135(52.6) \%$ & $56 / 168(33 \%)$ & \\
\hline Yes & $64 / 135(36.4 \%)$ & $112 / 168(66.7 \%)$ & 0.001 \\
\hline \multicolumn{4}{|l|}{$\begin{array}{l}\text { Medical supplies } \\
\text { shortages }{ }^{b}\end{array}$} \\
\hline Yes & $119 / 255(46.7 \%)$ & $136 / 255(53.3 \%)$ & 0.005 \\
\hline No & $12 / 48(25 \%)$ & $36 / 48(75 \%)$ & \\
\hline \multicolumn{4}{|l|}{ Occupation $^{b}$} \\
\hline Nurses/physicians & $101 / 228(44.3 \%)$ & $127 / 228(55.7 \%)$ & 0.5 \\
\hline Others & $30 / 75(40 \%)$ & $45 / 75(60 \%)$ & \\
\hline \multicolumn{4}{|l|}{ Family status ${ }^{b}$} \\
\hline Married/cohabited & $93 / 204(45.6 \%)$ & $111 / 204(54.4 \%)$ & 0.23 \\
\hline $\begin{array}{l}\text { Single/divorced/ } \\
\text { windowed }\end{array}$ & $38 / 99(38.4 \%)$ & $61 / 99(61.6 \%)$ & \\
\hline \multicolumn{4}{|l|}{ Type of hospital b } \\
\hline Tertiary/University & $79 / 148(53.4 \%)$ & $69 / 148(46.6 \%)$ & $<0.001$ \\
\hline Secondary & $52 / 155(33.5 \%)$ & $103 / 155(66.5 \%)$ & \\
\hline
\end{tabular}

\section{Univariate and multivariate analysis of depersonalization}

Table 4 gives the results of univariate analysis of depersonalization. Male sex, unsatisfactory rest after night shift, working as nursing personnel / physician, shortages of medical supplies and working at a tertiary/university hospital were factors significantly associated with a score in depersonalization scale $\geq$ 10. Multivariate (logistic regression) analysis confirmed that medical supplies shortages $(\mathrm{OR}=2.35$; $95 \%$ C.I. $=1.1-5.03)$, absence of satisfactory rest after nightshift (1.93; 95\%C.I. $=1.17-3.19)$, and working at a tertiary hospital $(\mathrm{OR}=1.72 ; 95 \%$ C.I. $=1.03-2.87)$ were independent predictors of depersonalization (table 5).

\section{Univariate and multivariate analysis of low personal accomplishment}

Table 6 indicates that cumulative amount of night work shifts and medical supplies shortages were significantly associated with a low personal accomplishment score $(\leq 33)$. Workers at the tertiary university hospital demonstrated lower personal accomplishment in comparison to their colleagues at the secondary hospital; however the difference was not significant. Logistic regression analysis confirmed that cumulative amount of night shifts (continuous variable; p-value: 0.037 ) and medical material shortages $(\mathrm{OR}=2.51 ; 95 \%$ C.I. $=1.14-5.51)$ were independent determinants of low personal accomplishment.

Table 5. Multivariate analysis of depersonalization.

\begin{tabular}{lll}
\hline Independent variables & \multicolumn{2}{c}{ Depersonalization $(+)$} \\
\cline { 2 - 3 } & OR $(95 \% \mathrm{CI})$ & P value \\
\hline Age & $1.003(0.97-1.03)$ & 0.857 \\
Mex & & \\
Female & $1.45(0.85-2.47)$ & 0.169 \\
Satisfactory rest after nightshift ${ }^{\mathrm{b}}$ & $1.00(\mathrm{ref})$ & \\
No & $1.93(1.17-3.19)$ & \\
Yes & $1.00(\mathrm{ref})$ & 0.036 \\
Medical supplies shortages & & \\
Yes & $2.35(1.1-5.03)$ & 0.027 \\
No & $1.00($ ref $)$ & \\
Type of hospital & & \\
Tertiary/University & $1.72(1.03-2.87)$ & 0.036 \\
Secondary & 1.00 (ref) & \\
\hline
\end{tabular}


Table 6. Univariate analysis of low personal accomplishment (PA).

\begin{tabular}{|c|c|c|c|}
\hline Variable & $\mathbf{P A}(+)^{*}$ & PA (-) & P value \\
\hline Sex ${ }^{b}$ & n (\%) & n (\%) & \\
\hline Male & $32 / 88(36.4 \%)$ & $56 / 88(63.6 \%)$ & $0.5^{\mathrm{b}}$ \\
\hline Female & $69 / 215(32.1 \%)$ & $146 / 215(67.9 \%)$ & \\
\hline Age (years) a & $38.5(8.01)$ & $39.6(9.56)$ & $0.3^{c}$ \\
\hline Cumulative night shifts ${ }^{a}$ & 640.6 & 506 & $0.019 \mathrm{~d}$ \\
\hline \multicolumn{4}{|c|}{ Satisfactory rest after nightshift ${ }^{b}$} \\
\hline No & $43 / 126(34.1) \%$ & $83 / 126(65.9 \%)$ & \\
\hline Yes & $58 / 176(33 \%)$ & $118 / 176(67 \%)$ & 0.6 \\
\hline \multicolumn{4}{|l|}{ Medical supplies shortages ${ }^{b}$} \\
\hline Yes & $92 / 255(36.1 \%)$ & $163 / 255(63.9 \%)$ & 0.02 \\
\hline No & $9 / 48(18.8 \%)$ & $39 / 48(81.2 \%)$ & \\
\hline \multicolumn{4}{|l|}{ Occupation $^{\mathrm{b}}$} \\
\hline Nurses/physicians & $73 / 228(32 \%)$ & $155 / 228(68 \%)$ & 0.4 \\
\hline Paramedics & $28 / 75(37.3 \%)$ & $47 / 75(62.7 \%)$ & \\
\hline \multicolumn{4}{|l|}{ Family status ${ }^{b}$} \\
\hline Married/cohabited & $74 / 204(36.3 \%)$ & $130 / 204(63.7 \%)$ & 0.15 \\
\hline Single/divorced/windowed & $27 / 99(27.3 \%)$ & $72 / 99(72.7 \%)$ & \\
\hline \multicolumn{4}{|l|}{ Type of hospital b } \\
\hline Tertiary/University & $55 / 148(37.2 \%)$ & $93 / 148(62.8 \%)$ & 0.181 \\
\hline Secondary & $46 / 155(29.7 \%)$ & $109 / 155(70.3 \%)$ & \\
\hline
\end{tabular}

a mean, standard deviation, ${ }^{\mathrm{b}} \mathrm{X}^{2}$ test, c Student's-t- test, ${ }^{\mathrm{d}}$ Mann Whitney test.

* Personal accomplishment (low): score $</=33$.

\section{Discussion}

This pilot study shows that the overall prevalence of the three dimensions of high burnout (emotional exhaustion, depersonalization, low personal accomplishment) was $44.5 \%, 43.2 \%$ and $51.5 \%$, respectively after 6 years of economic deceleration. This is an important observation since it can be used as base line information for future comparisons. The prevalence of burnout among health care workers varies greatly in the international literature. In Greece, Msaouel et al in a cross-sectional study among medical residents found a prevalence (high burnout): $56.6 \%, 66.2 \%$, and $58.5 \%$ for emotional exhaustion, depersonalization and low personal accomplishment, respectively [10]. Panagopoulou et al in a descriptive study among internal medicine specialists found a prevalence $49.6 \%$ and $61 \%$ for high emotional exhaustion and depersonalization, respectively [11]. Soler et al in European study among family doctors found among Greek family practice doctors a prevalence for high emotional exhaustion, depersonalization and low personal accomplishment: 31.1\%, 73.3\% and $91.1 \%$, respectively [9]. The corresponding prevalence figures for European Family doctors were $43 \%$, $35.3 \%$ and $32 \%$, respectively. Moreover Aiken et al in a large cross-sectional survey among nurses in 12 European countries and United States found a burnout rate among nurses ranged from $10 \%$ in Netherlands to $78 \%$ in Greece [12]. Regarding socio-demographic risk factors of burnout our study has shown that age was a significant predictor of emotional exhaustion. We did not found significant associations between other socio-demographic factors (sex, marital status) and depersonalization or low personal accomplishment. Several studies have shown heterogeneity of findings regarding socio-demographic factors and burnout among health care workers [13 14,15]. Regarding occupation, a recent review suggested that nurses have been found to experience higher levels of burnout in comparison to other health care workers [16]. However, there are also several studies indicating that the frequency of emotional exhaustion was higher among physicians $[17,18]$. To our knowledge there are sparse data on burnout among paramedical personnel. The present study indicates that nursing personnel and physicians presented similar levels of burnout (in all dimensions of burnout) and recorded a higher risk for emotional exhaustion in comparison to paramedical personnel. It is difficult to provide an interpretation for this finding, and we could assume that public hospital budget cuts may have equally affected both nursing personnel and physicians. Night work shifts proved an independent risk factor for low personal accomplishment in our study. However cumulative amount of work shifts were not associated with emotional exhaustion and depersonalization. The evidence regarding the association between night shifts and burnout is inconsistent. Poncet et al in a large study of burnout syndrome among critical care nursing staff in France found no correlation between number of night shifts and burnout [19]. On the contrary Embriaco and 
co-workers in a national survey among intensivists in France found an independent association between night shifts and burnout [13]. Furthermore insufficient rest after a night shift was an independent predictor of emotional exhaustion and depersonalization.

The most interesting finding of the present survey is that $88 \%$ of the participants reported medical supplies shortages during the last 12 months and also these shortages have a negative impact on the healthcare provided to the patients. Further, it is worth mentioning that medical supplies shortages appeared as a strong predictor of emotional exhaustion and depersonalization in this pilot study. Our study has several limitations which should be considered prior to interpretation of the results. It is a cross-sectional design and thus, we are unable to identify causal relationships between risk factors and dimensions of burn out syndrome. Another limitation is related to the generalizability of our results which cannot be applied across the board of all health care workers in Greece. A last limitation is that we did not ask participants about additional workplace risk factors related to burnout. Such factors should be investigated in a future and larger scale research.

\section{Conclusion}

In conclusion, we found an alarming prevalence of medical supply shortages in two Greek hospitals and these shortages found to have negatively impacted the quality of the healthcare provided to the patients. Medical supply shortages were significantly associated with emotional exhaustion and depersonalization among health care workers. The above finding- if confirmed by future research- provides preliminary evidence that austerity has deregulated the Greek hospitals. Moreover, the medical supply shortages in Greek hospitals may reflect the unfolding humanitarian crisis in Greece.

\section{Competing Interests}

The authors have declared that no competing interest exists.

\section{References}

1. Maslach C, Schaufeli WB, Leiter MP. Job burnout. Annu Rev Psychol. 2001;52:397-422.

2. Schaufeli WB, Leiter MP, Maslach C. Burnout: 35 years of research and practice. Career Development International 2009;14:204-220.

3. Kentikelenis A, Karanikolos M, Papanicolas I, Basu S, McKee $M$, Stuckler D. Health effects of financial crisis: omens of a Greek tragedy. Lancet. 2011;378:1457-8.

4. Telloglou T, Kakaounaki M.Three weeks and one night on duty. In Papahelas A, Telloglou T,Papaioannou S, eds. Folders. Greece: Skai TV, 2011.

5. Karanikolos M, Mladovsky P, Cylus J, Thomson S, Basu S, Stuckler D, Mackenbach JP, McKee M. Financial crisis, austerity, and health in Europe. Lancet. 2013;381:1323-31.
6. [Internet] AHEPA HELLAS. AHEPA Addresses Medical Supply Shortage Helps Secure $\$ 650,000$ Shipment. http:/ / ahepahellas.org/news/ahepas-humanitarian-campaign -for-greece-addresses-medical-supply-shortage-helps-secure-65 0000-shipment.

7. Spânu F, Băban A, Bria M, Dumitrascu DL. What happens to health professionals when the ill patient is the health care. Br J Health Psychol. 2013;18:663-79. doi: 10.1111/bjhp.12010. Epub 2012 Dec 6.

8. Maslach C, Jackson SE. Maslach Burnout Inventory. $2^{\text {nd }}$ edn. Palo Alto, CA: Consulting Psychologists Press, 1986.

9. Soler JK, Yaman H, Esteva M, Dobbs F, Asenova RS, Katic M, Ozvacic Z, Desgranges JP, Moreau A, Lionis C, Kotányi P, Carelli F, Nowak PR, de Aguiar Sá Azeredo Z,Marklund E, Churchill D, Ungan M; European General Practice Research Network Burnout Study Group. Burnout in European family doctors: the EGPRN study. Fam Pract. 2008;25:245-65. doi: 10.1093/fampra/cmn038. Epub 2008 Jul 11.

10. Msaouel P, Keramaris NC, Tasoulis A, Kolokythas D, Syrmos N, Pararas N, Thireos E, Lionis C. Burnout and training satisfaction of medical residents in Greece: will the European Work Time Directive make a difference? Hum Resour Health.2008; 8(1):16. doi: 10.1186/1478-4491-8-16.

11. Panagopoulou E, Montgomery A, Benos A. Burnout in internal medicine physicians: Differences between residents and specialists. Eur J Intern Med. 2006; 17:195-200.

12. Aiken LH, Sermeus W, Van den Heede K, Sloane DM, Busse R, McKee M, Bruyneel L,Rafferty AM, Griffiths P, Moreno-Casbas MT, Tishelman C, Scott A, Brzostek T,Kinnunen J, Schwendimann R, Heinen M, Zikos D, Sjetne IS, Smith HL, Kutney-Lee A. Patient safety, satisfaction, and quality of hospital care: cross sectional surveys of nurses and patients in 12 countries in Europe and the United States. BMJ. 2012; 344(e):1717. doi: 10.1136/bmj.e1717.

13. Embriaco N, Azoulay E, Barrau K, Kentish N, Pochard F, Loundou A, Papazian L. High level of burnout in intensivists: prevalence and associated factors. Am J Respir Crit Care Med. 2007;175:686-92. Epub 2007 Jan 18.

14. Ozyurt A, Hayran O, Sur H. Predictors of burnout and job satisfaction among Turkish physicians. QJM. 2006; 99:161-9.

15. Thomas NK. Resident review. JAMA 2004; 292:2890-2889.

16. Khamisa N, Peltzer K, Oldenburg B.Burnout in relation to specific contributing factors and health outcomes amongnurses: a systematic review. Int J Environ Res Public Health. 2013;10:2214-40. doi:10.3390/ijerph10062214.

17. Escribà-Agüir V, Martín-Baena D, Pérez-Hoyos S. Psychosocial work environment and burnout among emergency medical and nursing staff. Int Arch Occup Environ Health. 2006; 80:127-33.

18. Schaufeli W. Burnout. In :Firth-Cozens J, Payne R (eds). Stress in health professionals, John Willey \& Sons, New York, 1999;: 17-32.

19. Poncet MC, Toullic P, Papazian L, Kentish-Barnes N, Timsit JF, Pochard F, Chevret S, Schlemmer B, Azoulay E. Burnout syndrome in critical care nursing staff. Am J Respir Crit Care Med 2007; 175:698-704. Epub 2006 Nov 1. 